\title{
OCT embedded sections of pathological specimens as a source of high quality RNA for reverse transcriptase/polymerase chain reaction
}

\author{
J A E Irving, G Cain, A Parr, M Howard, B Angus, A R Cattan
}

\begin{abstract}
OCT embedded cryostat sections of stored pathological specimens of non-Hodgkin's lymphoma were used to provide RNA. After reverse transcription to produce cDNA, the polymerase chain reaction was performed with primers for standard and variant forms of the CD44 molecule. Using Southern transfer and hybridisation with a probe specific for exon 4 of the CD44 gene, both standard and variant forms were visualised by autoradiography. This method was shown to be applicable to other gene products by using primers specific for the $a b l$ and $b c r$ genes. This technique permits retrospective analysis of RNA from small amounts of stored pathological samples.

(f Clin Pathol 1996;49:258-259)
\end{abstract}

Keywords: RNA, RT-PCR, cryostat sections, CD44.

CD44 is a ubiquitous cell surface glycoprotein that serves as an adhesion molecule in cellsubstrate and cell-cell interactions, including lymphocyte homing, haematopoiesis, cell migration, and metastasis. ${ }^{12}$ The molecule exists as a number of isoforms, generated by alternative splicing of 10 variant exons. ${ }^{3}$ The function and regulation of CD44v molecules is poorly understood but it is known that there is differential expression of variant exons by various epithelia. ${ }^{4}$ The CD44 molecule expressing variant 6 (exon 11) seems to relate to tumour progression, particularly the metastatic potential of some cancers. ${ }^{5}$ In retrospective analysis of breast cancer CD44v6 expression was correlated with poor overall survival. ${ }^{6}$

Here, we report the use of cryostat sections as an alternative source of high quality RNA for visualising CD44 and its variants in nonHodgkin's lymphoma by reverse transcriptase/ polymerase chain reaction (RT-PCR).

\section{Methods}

ISOLATION OF RNA

Five pooled cryostat sections $(20 \mu \mathrm{m})$ were stored frozen at $-20^{\circ} \mathrm{C}$ in a GITC (guanidine isothiocyanate) solution. After thawing, samples were homogenised using a battery operated disposable mortar and pestle (Anachem, Luton, UK). The method of Chirgwin et $a l^{7}$ was used to isolate RNA after caesium chloride ultracentrifugation, phenol/chloroform ex- traction and ethanol/salt precipitation. Denaturing formaldehyde gel electrophoresis was used to assess the quality of the RNA.

\section{CDNA PREPARATION AND POLYMERASE CHAIN} REACTION

The method of Cross $e t \mathrm{al}^{8}$ was used to reverse transcribe about $5 \mu \mathrm{g}$ RNA, using random hexamers and M-MLV (Life Technologies, Paisley, Scotland). PCR primers and reaction conditions were as described by Matsumura and Tarin $^{5}$ for CD44 and by Cross et $a l^{9}$ for $b c r$ and $a b l$. PCR products were analysed by gel electrophoresis using 3\% Nusieve agarose (FMC Bioproducts, Rockland, Maine, USA) and photographed after staining with ethidium bromide.

BLOTTING AND PROBING

After Southern blotting onto Genescreen (NEN, Boston, Massachusetts, USA), filters were hybridised with end-labelled probes as described by Matsumura and Tarin ${ }^{5}$ and developed as autoradiographs using standard techniques.

\section{Results and Discussion}

Denaturing gel electrophoresis of purified RNA showed distinctive $28 \mathrm{~S}$ and $18 \mathrm{~S}$ RNA which can be routinely extracted from frozen sections of lymph nodes, currently dating back three years (figure, panel A). Triplicate $20 \mu \mathrm{m}$ sections were used for RNA extraction initially; however, we were unable to obtain sufficient RNA from many samples. As a consequence, we now routinely pool five sections per sample which has permitted successful RT-PCR analysis of CD44 expression and subsequent analysis by Southern blotting of CD44 variants in 28 of 30 samples (figure, panels B and C). We have been able to show that RNA extracted by this method is suitable for the analysis of other gene products-for example, $b c r$ and the housekeeping gene, $a b l$ (figure, panel B).

This technique permits retrospective analysis of small amounts of stored pathological samples. Results may then be correlated with clinical outcome. This may be particularly important for CD44 expression as there is an ever increasing list of malignancies in which CD44v expression, particularly variant 6 , is a marker of metastasis and thus prognosis. Although immunocytochemical techniques with specific 
A

B

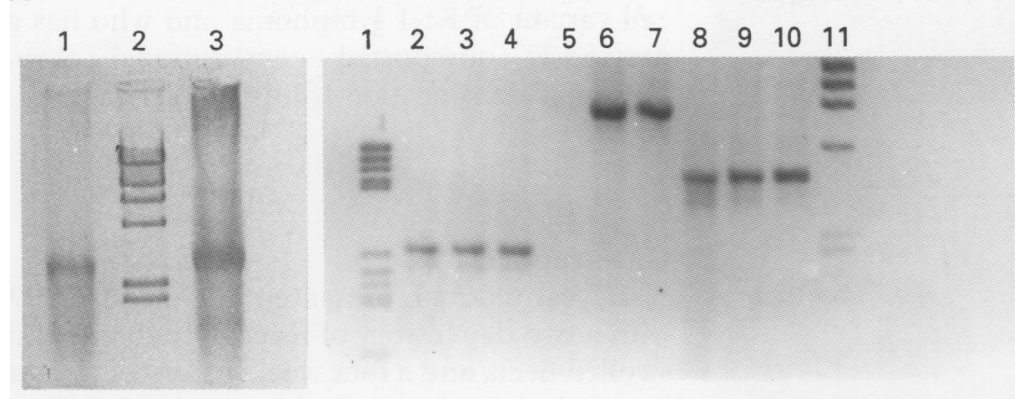

C

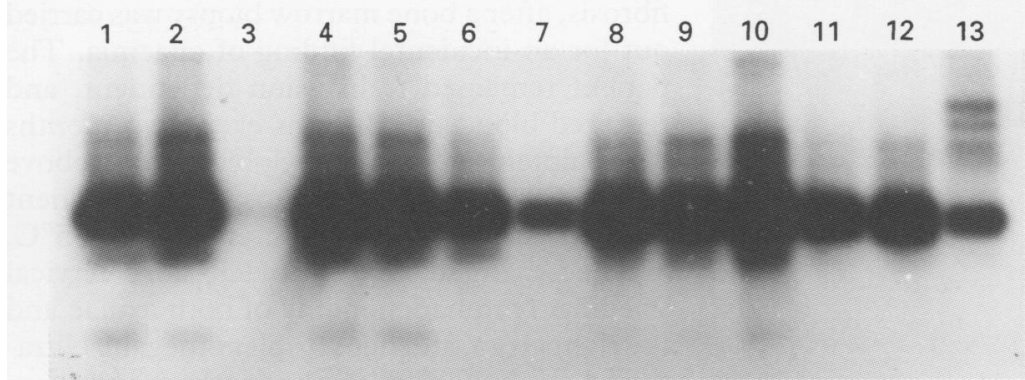

(A) Formaldehyde agarose electrophoretic gel of RNA. Lanes 1 and 3, $3 \mu \mathrm{g} R \mathrm{RA}$ extracted from OCT embedded sections of samples from two patients with non-Hodgkin's lymphoma; lane 2, $\lambda$ HindIII markers. (B) Agarose electrophoretic gel of PCR products. RNA was extracted from three different samples from patients with non-Hodgkin's lymphoma as outlined in the methods section and reverse transcribed into cDNA. An aliquot of each was used as a substrate for PCR using three different amplimer sets. Lanes 2-4, abl; lanes 5-7, bcr; lanes 8-10, CD44; lanes 1 and 11, pBR322 AluI and $\phi X 174$ HaeIII, respectively, as base pair markers. (C) Analysis of CD44 isoforms in non-

Hodgkin's lymphoma samples after PCR and hybridisation with a radiolabelled oligoprobe to a non-variant part of the molecule (exon 4). Note: lane 3 in panel A, lanes 3, 6 and 9 in panel $B$ and lane 9 in panel $C$ represent $R N A, P C R$ products and blot of the same frozen non-Hodgkin's lymphoma sample, respectively.

antibodies can detect variant expression in cryostat sections, the PCR method may detect small numbers of CD44v positive cells, not apparent by antibody staining because of a lack of sensitivity or masking of the antigenic sites. ${ }^{10}$ Combining the method described here with immunohistochemistry on sequential sections may permit a more detailed analysis of cell phenotype. In addition, PCR analysis followed by Southern blotting gives additional information on the fingerprint pattern of variant expression, which may have biological implications.

We wish to thank the North East Cancer Research Campaign and the Tyneside Leukaemia Research Fund for their support.

1 East JA, Hart IR. CD44 and its role in tumour progression and metastasis. Eur $\mathcal{F}$ Cancer 1993;29A:1921-2.

2 Ruiz P, Schwärzler C, Günthert U. CD44 isoforms during differentiation and development. Bioessays 1995;17:17-24.

3 Screaton GR, Bell MV, Jackson DG, Cornelius FB, Gerth $\mathrm{U}$, Bell JI. Genomic structure of DNA encoding the , Bell Jl. Geninic structure 40 least 12 alternatively spliced exons. Proc Natl Acad Sci USA 1992; 89:12160-4.

4 Mackay CR, Terpe H-J, Stauder R, Marston WL, Stark H, Günthert U. Expression and modulation of CD44 variant isoforms in humans. $\mathcal{F}$ Cell Biol 1994;124:71-82.

5 Matsumura Y, Tarin D. Significance of CD44 gene products for cancer diagnosis and disease evaluation. Lancet 1992; 340:1053-8.

6 Kaufmann M, Heider K-H, Sinn H-P, Von Minckwitz G, Ponta H, Herrlich P. CD44 variant epitopes in primary breast cancer and length of survival. Lancet 1995;345: 615-19.

7 Chirgwin JM, Przybyla AE, McDonald R, Rutter WJ. Isolation of biologically active ribonucleic acid from sources ation of biologically active ribonucleic acid from source

8 Cross NCP, Feng L, Bungey J, Goldman JM. Minimal residual disease after bone marrow transplant for chronic myeloid leukaemia detected by the polymerase chain reaction. Leuk Lymphoma 1993;11:39-43.

9 Cross NCP, Melo JV, Feng L, Goldman JM. An optimized multiplex polymerase chain reaction (PCR) for detection of bcr/abl fusion mRNAs in haematological disorders. Leukemia 1994;8:186-9.

10 Dall P, Heider K-H, Sinn H-P, Skroch-Angel P, Adolf G, Kaufmann M, et al. Comparison of immunohistochemistry and RT-PCR for detection of CD44v expression, a new prognostic factor in human breast cancer. Int $\mathcal{F}$ Cancer prognostic factor

\section{Department of} Clinical Oncology,

Sir Y K Pao Cancer

Centre, Chinese

University of Hong

Kong, Prince of Wales

Hospital, Shatin

N. T., Hong Kong

W Yeo

N Wong

P J Johnson

N Wickham

\section{Department of
Anatomical and}

Cellular Pathology

J Chow

W C Tsoi

Correspondence to: Dr Nicholas Wickham Department of Clinica Oncology, Prince of Wales Hospital, Shatin N. T., Hong Kong.

Accepted for publication 18 October 1995

\section{Small cell variant of $\mathrm{Ki}-1$ lymphoma associated with myelofibrosis and a novel constitutional chromosomal translocation $\mathrm{t}(3 ; 4)(\mathrm{q} 13 ; \mathrm{q} 12)$}

\author{
W Yeo, N Wong, J Chow, W C Tsoi, P J Johnson, N Wickham
}

\begin{abstract}
An unusual case of small cell variant of Ki-1 non-Hodgkin's lymphoma diagnosed one year after an original diagnosis of idiopathic myelofibrosis is reported. On the second occasion, the patient presented with fever, lymphadenopathy and hepatosplenomegaly. A lymph node biopsy specimen confirmed a diagnosis of small cell variant of $\mathrm{Ki}-1$ lymphoma. A repeat bone marrow biopsy specimen showed myelofibrosis with no evidence of lymphomatous infiltration, but cytogenetic studies on blood, bone marrow and skin
\end{abstract}

fibroblasts revealed a novel chromosomal translocation $t(3,4)(q 13 ; q 12)$.

(f Clin Pathol 1996;49:259-262)

Keywords: Ki-1 lymphoma, myelofibrosis.

Small cell $\mathrm{Ki}-1$ lymphoma is a variant of $\mathrm{Ki}-1$ anaplastic large cell lymphoma (ALCL), which has been described recently. ${ }^{1}$ The specific chromosomal translocation $\mathrm{t}(2 ; 5)(\mathrm{p} 23 ; \mathrm{q} 35)$ has been a consistent finding in association with both variants of $\mathrm{Ki}-1$ lymphoma ${ }^{1-3}$ Lymphoma is a recognised, albeit uncommon, cause of myelofibrosis. However, idiopathic myelo- 